\title{
Eu estava espionando meu vizinho quando
}

Luiza Crosman*

RESUMO: O ensaio é parte da obra Eu estava espionando meu vizinho quando, realizada entre Outubro de 2013 e Maio de 2015, e apresentada recentemente como comunicação oral performativa no $3^{\circ}$ Simpósio LAVITS - vigilância, tecnopolíticas e territórios, no Rio de Janeiro. A obra constitui-se também de uma série de vídeos editados, capturados de madrugada, do vizinho da artista. Neste presente texto, a partir dos conceitos de dispositivo e vigilância distribuída de Fernanda Bruno e Anne Marie Duguet, performatividade, de Ana Bernstein e Eleonora Fabião, e escritos próprios em diferentes tons, a artista elabora uma investigação teórica e prática acerca da performatividade do ato de olhar e procura expandir o ato performativo em sua possibilidade de escrita.

PALAVRAS CHAVE: vigilância contemporânea, performatividade, escrita experimental.

ABSTRACT: This essay is part of the work "I was spying on my neighbor when", made between October 2013 and May 2015 and recently presented as a performative lecture in the 3rs LAVITS Symposium - surveillance, tecnopolitics and territories, at Rio de Janeiro. The work also comprises a series of edited videos, captured at night of the artist's neighbor. In the present text, the concepts of device, surveillance and perfomativity are explored through authors Anne Marie Duguet, Fernanda Bruno, Ana Bernstein and Eleonora Fabião respectively. Also, personal writings of the artists are put together to elaborate a theoretical and pratical investigation on the act of seeing, its performativity and a possible performative writing.

KEYWORDS: contemporary surveillance, performativity, experimental writing.

*Luiza Crosman é artista e Mestre em processos artísticos contemporâneos, UERJ. 


\section{Introdução}

A obra Eu estava espionando meu vizinho quando, realizada por mim entre Outubro de 2013 e Maio de 2015, é composta por uma série de vídeos editados de imagens capturadas de meu vizinho em sua varanda durante várias noites seguidas, anotações literárias que acompanharam as madrugadas de espionagem, um artigo e uma comunicação oral performativa - esta última escrita e apresentada no contexto do $3^{\circ}$ simpósio LAVITS - vigilância, tecnopolíticas e territórios, no dia 14 de Maio de 2015. Cada uma dessas manifestações, embora dividam o mesmo fundo conceitual de exercer a ação vigilante, apresentam especificidade e um ritmo próprios, sendo, portanto complementares, porém autônomas. Neste artigo, pretendi articular não só as questões teóricas tangentes à obra, como também questões da sua própria escrita, tornando-o então algo para além da base teórica do trabalho: um meta-documento, estético e investigativo, que pensa a linguagem discursiva também como prática performativa. A motivação desse exercício advém de dois fatores: o fato de a própria obra já prever ferramentas discursivas - as breves frases ou parágrafos escritos ao longo do período de espionagem; e o desejo de proporcionar tensão à fronteira entre escrita e performance. Ambos os fatores acabam por conferir ao processo da obra certa consciência pública de si mesma, pois tanto sua fatura quanto sua problematização frente aos seus aspectos estéticos, e também éticos, são incorporadas ao trabalho e ficam dispostas para o leitor ou espectador.

Em relação à comunicação oral performativa, foi através da projeção dos vídeos de registro e da leitura dos escritos referentes ao trabalho que essa autoconsciência serviu também para tornar o público um público cúmplice, pois foi na sua apresentação que emergiu uma espécie de meta-vigilância, salientando na prática as relações entre ver e ser visto, o público e o privado, o real e o ficcional e a vigilância e o espetáculo. Este artigo recorre a essas quatro duplas conceituais como forma de traçar um perímetro de pesquisa teórica e prática ao redor do ato de olhar. Mas, no seu desenvolvimento, a aparente dualidade dos conceitos dá lugar a uma topografia mais complexa e disforme, formada a partir da articulação entre os conceitos de vigilância distribuída e dispositivo, postos por Fernanda Bruno e Anne-Marie Duguet, respectivamente, e as relações entre performance e cena apresentadas por Eleonora Fabião e elaboradas em conjunto com a definição de ato performativo, problematizado por Ana Berstein. Finalmente, essa topografia é composta também por algumas das anotações 
literárias produzidas ao longo do trabalho. Os tempos verbais desses trechos variam, assim como os estilos de narração, e é importante ressalvar que não aparecem neste documento na sua ordem cronológica de escrita e nem na íntegra do conjunto.

Atenção: o conteúdo a seguir pode ter caráter íntimo.

Diana, deusa e rainha da caça, banhava-se quando foi surpreendida pelo olhar de Actéon. Em seu estado mais vulnerável, nua, despida de suas roupas e armas, entregue aos cuidados íntimos, vestiu-se primeiro de vergonha, e em seguida, de ira. Ela, deusa da caça, Ele, exímio caçador; antes, equiparados de um mesmo lado da espreita. O símbolo da caça não pode ser reconhecido em sua vulnerabilidade e nada fazer. Seria o aval, a permissão. Seria reconhecer que uma vez caçador, outra presa. Mas Diana é deusa, não se submete à segunda condição.

Actéon caça e por isso se sente à vontade no bosque, vagueia e contempla. Não imagina ser traído pela sua cotidiana e constante condição de olhar atento. Esbarra em Diana e suas ninfas e vê o que não poderia. Testemunha o corpo nu da deusa e é revertida sua posição de caçador. Sofre na própria carne o ataque que a outros seres do bosque infligiu.

A primeira vez que notei sua varanda foi ao perceber uma única janela que emanava luz enquanto todo o prédio estava no absoluto breu. Uma luz inconstante e azulada me informava que meu vizinho estava assistindo televisão. Foi no dia $1^{\circ}$ de Outubro de 2013. Ao acender, a varanda revelava a silhueta de plantas que ocupavam o espaço. Filmei para registrar o momento. Interessava-me a alternância entre informação e silêncio visual. Os clarões revelavam a forma das plantas e o ritmo da televisão. Ao olhar pelo visor da câmera notei uma luz diferente, também azulada, mas mais intensa, uma luz pontual. Olhando com mais atenção, vi uma silhueta, diferente da das plantas, se mover.

Meu vizinho fumava na varanda.

Escondido pela escuridão, disfarçado pelas outras silhuetas.

Na revelação da sua presença foi que me dei conta do que estava fazendo.

Percebi que o espionava. 


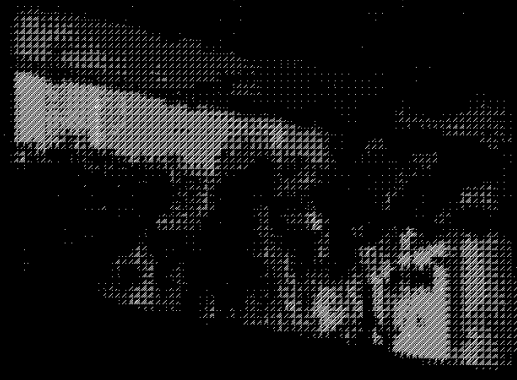

\section{Luiza Crosman}

Eu estava espionando meu vizinho quando, 2015.

Still de vídeo da comunicação oral performativa

(Fonte/fotógrafa: Lua Perê, 2015.)

Depois que comecei não posso mais parar. Sou ao observá-lo durante horas seguidas, embora não o faça sistematicamente. Quando o olho pela minha janela, a noite faz um excelente trabalho em encobri-lo. Faço questão de filmá-lo ao mesmo tempo em que o espiono. Retenho em vídeo sua figura, e assim a vejo melhor. 


\section{UM}

Cada período histórico possui seus regimes de visibilidade, que são, dentre outros fatores, associados às tecnologias e às relações de poder estabelecidas em seu tempo. Em seu livro Máquinas de ver, modos de ser, a autora Fernanda Bruno explora as mudanças ocorridas nos modos de ver na passagem da modernidade para a atualidade. A partir dos filósofos Gilles Deleuze e Michel Foucault, a autora conceitua um regime de visibilidade não como aquilo que é visto, mas como aquilo que torna possível o que se vê. Ou seja, porque cada período histórico tem seu próprio regime, não há atributos ou atos de um sujeito universal da visão, nem dados empíricos que possam originar condições de visibilidade. Estas são, na realidade, formadas por "máquinas, práticas, regras e discursos que estão articulados a formações de saber e jogos de poder" (BRUNO, 2013, p15).

Assim como os regimes de visibilidade, os dispositivos de vigilância a partir da modernidade não são exteriores às dinâmicas sócio-culturais, mas the são imanentes. Além de estarem alinhados a fatores de ordem tecnológica e de comportamento, são também produto de procedimentos de poder com caráter positivo que prometem trazer ao Estado e suas populações ordem, saúde, segurança, sendo, pois intrínsecos às ideias de modernização e melhores práticas da administração da vida moderna. É justamente por estarem alinhados a tais fatores, que os dispositivos de vigilância são legitimados. Tais dispositivos não podem ser vistos, portanto, essencialmente como mecanismos de repressão ou forças externas de dominação, embora, como adverte a autora - e como mostra Foucault em sua conceituação acerca das sociedades disciplinares - fossem também máquinas de curar, reformar, normalizar e punir.

Ainda segundo Bruno, é possível buscar na modernidade dois pontos que conduzem a vigilância moderna para a contemporânea: de um lado, os processos de modernização da visão e de constituição de uma cultura do espetáculo, e de outro, os processos disciplinares. Bruno, de modo geral, delimita três elementos centrais e interligados como definição de uma atividade vigilante: observação, conhecimento e intervenção. A observação implica a inspeção regular, sistemática e focalizada do vigiado, permitindo a produção de conhecimento de modo a possibilitar agir sobre suas condutas e, assim, funciona como intenção de intervenção sobre os indivíduos ou população em questão.

No entanto, o aspecto da vigilância moderna desenvolvido pela autora que mais interessa a esse texto não é o seu potencial de intervenção, mas sim a naturalização progressiva da 
atividade vigilante que resulta na vigilância distribuída das sociedades contemporâneas. Uma vigilância que passa a incorporar processos de entretenimento e sociabilidade e torna-se um regime de visibilidade capaz de produzir subjetividade. Por conta do enfoque, as determinações da vigilância nas sociedades disciplinares e em seu contexto moderno não serão amplamente investigadas nesse artigo, apesar disso, alguns dos processos de legitimação modernos serão tratados de forma breve para que se possa traçar o percurso para a nossa atualidade.

Segundo Bruno, parte significativa da vigilância contemporânea é herdeira do desejo de eficiência, velocidade, controle e coordenação da administração da sociedade moderna. Esses desejos eram supridos através de procedimentos disciplinares, que, como já dito acima, tidos como positivos, permitiam ao Estado o controle e normalização das condutas individuais. 0 principal elemento de vigilância do controle disciplinar, o modelo do panóptico, exerce sua influência pela constância de seu olhar, que mesmo inverificável - e, em alguns casos, justamente por isso - serve a produzir o controle em sistemas centralizados e hierarquizados. A noção de vigilância distribuída que Bruno opera para tratar da vigilância contemporânea serve para contestar a noção de que as tais práticas são hoje como um modelo do panóptico hipertrofiado. A autora defende a necessidade de usar outro termo, justamente pela ampla diferenciação entre o modelo do panóptico e o da vigilância distribuída, que se caracteriza por ser: descentralizada, formada em rede e distribuída entre indivíduos, instituições e agentes não humanos; múltipla, podendo ser, por exemplo, delegada a sistemas técnicos automatizados, exercida a distância, em tempo real e em intensidade que vai além do limite humano; nebulosa, na diferenciação entre vigias e vigiados; imprevisível, porém potencial, no sentido de que atua em deslocamentos entre os potenciais e as finalidades dos dispositivos que a integram; presente nos circuitos de entretenimento e prazer, uma vez que a subjetividade contemporânea encontra na vigilância distribuída não só uma forma de controle e proteção como também sociabilidade e prazer; e, finalmente, para além de unilateral e hierarquizada, é também coletiva, motivando os indivíduos a adotarem um olhar vigilante uns sobre os outros, sobre a cidade e o mundo.

O olho exerce uma pressão sobre o mundo. É comum sentir essa pressão na nuca, em um ponto equidistante acima dos dois olhos e algumas pessoas dizem sentir também nas laterais das costas, próximo às axilas. $\mathrm{O}$ que esses três pontos tem em comum é que não é possível 
protegê-los os três ao mesmo tempo do olhar inquisidor. Caso leve-se as mãos trançadas à nuca, e com a junção dos cotovelos esconder o rosto, as laterais ficam expostas. Se, ao sentir a pressão, o corpo tem uma reação diferente e contrai-se, abraçando a si mesmo pela frente, e erguendo os ombros, a nuca e as laterais ficam seguras, mas à custa do sensível ponto entre os olhos. Também pode se levantar o braço em direção a esse ponto, virando inclusive o pescoço um pouco de lado; mas é claro que novamente as laterais do corpo ficam expostas. $\mathrm{E}$, caso a tentativa de se proteger seja abaixando o torso em direção à barriga e levando as mãos ao rosto, a nuca, totalmente exposta, arrepia-se pela vulnerabilidade.

(Nota-se que todas essas posturas podem ser realizadas de olhos abertos e ainda atentos ao seu redor).

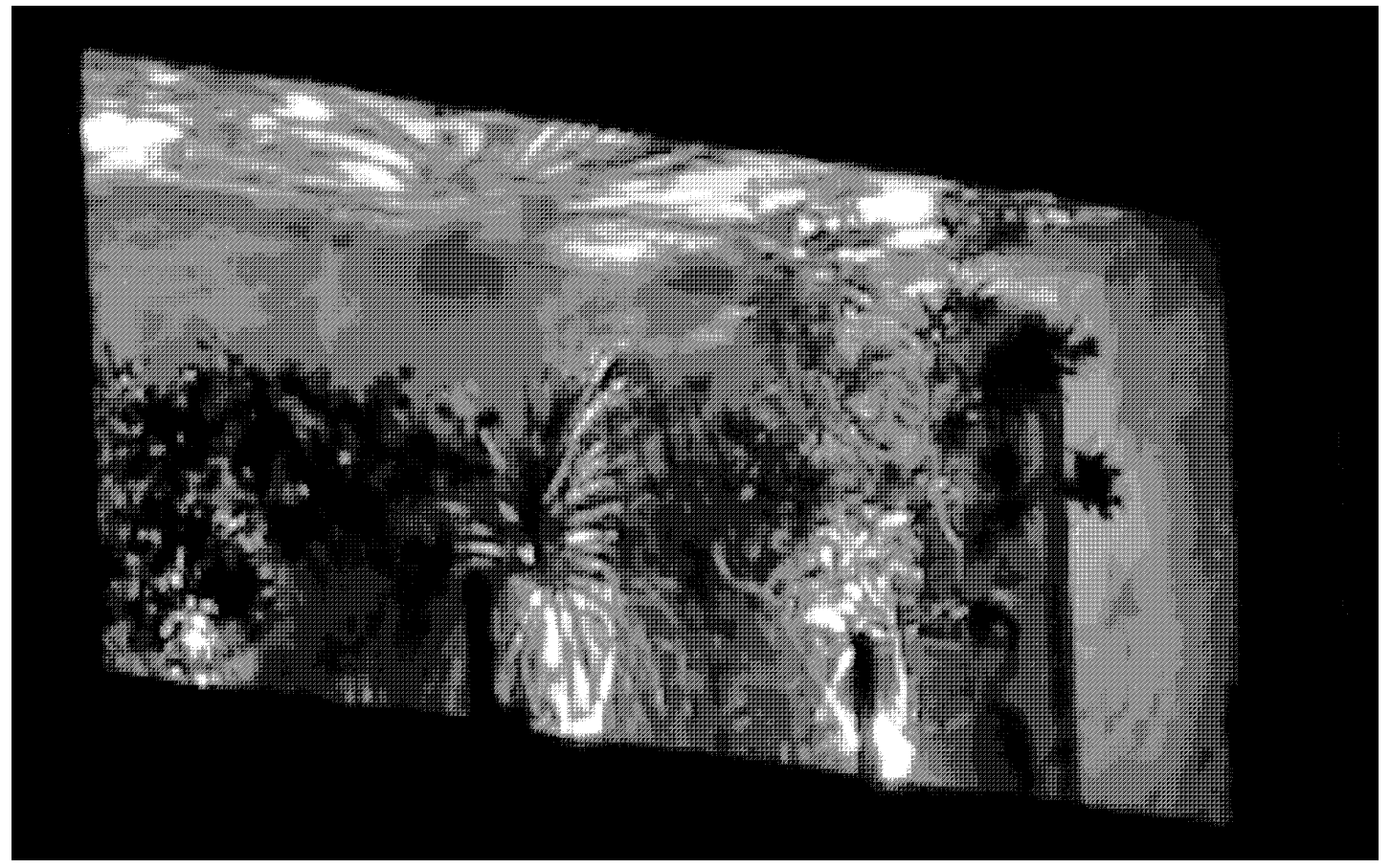

\section{Luiza Crosman}

Eu estava espionando meu vizinho quando, 2015.

Detalhe de still de vídeo da comunicação oral performativa

(Fonte/fotógrafa: Lua Perê, 2015.) 
O aspecto social da vigilância contemporânea encontra sua raiz na cultura visual emergente do contexto moderno. Novas tecnologias de produção e reprodução de imagem, deslocadas para a vida urbana, estimularam os sujeitos a serem não só produtores como também espectadores. Atualmente, somos todos capazes de operar diversas tecnologias que nos permitem produzir, editar e compartilhar registros visuais do nosso cotidiano urbano. O automonitoramento ${ }^{1}$ e auto-publicação online participam de um processo onde o cuidado de si, a otimização de performance e o cotidiano íntimo são expostos a fim de viabilizar a produção de uma subjetividade em conjunto com o coletivo que a testemunha e valida. Redes sociais, aplicativos de compartilhamento de foto e vídeo e os reality-shows são os exemplos mais atuais de tal processo. É em meio a esta recorrente produção de imagens e autoimagens que a vigilância contemporânea se faz presente também em circuitos de intimidade e entretenimento, em um movimento no qual não só se vale de dispositivos como se torna ela mesma um dispositivo de produção de subjetividade. Ao falar de dispositivo, Bruno, refere-se aos três traços centrais que o constituem - um conjunto de elementos heterogêneos; uma função estratégica; jogos e formações de poder e saber - salientando, porém, que o potencial do dispositivo refere-se mais à rede de relações que engendra do que a estes elementos. $E$, porque as relações de força, funções e posições de tais elementos são móveis, da mesma forma que configuram os circuitos de vigilância, por exemplo, são também por eles configurados. Ressalto aqui um dos principais aspectos da estética da vigilância que interessa a esse texto e obra: a noção de que o sujeito, aquele que vê, não está na origem dos regimes de visibilidade. Pelo contrário, é de diferentes modos, "uma função derivada, um agente entre outros" (BRUNO, 2013, p15).

\section{DOIS}

Em um paralelo, nos processos em arte contemporânea, a noção de dispositivo, articulada por Anne-Marie Duguet em seu texto "Dispositivos", implica tanto em situações institucionais quanto em processos de percepção. Para Duguet foram as experimentações relativas aos dispositivos de vídeo, para além de sua exibição apenas como projeção, que contribuíram mais intensamente para novas concepções de obra na arte contemporânea. A entrada desses dispositivos instalações e performances anunciou a possibilidade teatral da obra, tanto como princípio crítico quando como modo de existência. O vídeo como possibilidade multimidiática 
nas experimentações ${ }^{2}$ de happenings, pop art, performance e arte minimalista corrompeu o processo modernista de avaliar uma obra pela sua pureza de meios ou autonomia de contexto. Segundo a autora, embora várias realizações explorem questões puramente formais baseadas em sua especificidade e princípios técnicos, é ao convocar contexto e referência e ocupar o lugar paradoxal de hibridismo com outros meios, que o vídeo participa do deslocamento e perda de fronteiras da obra de arte, especialmente em sua relação com o sujeito-espectador.

Para realizar essa proposição, a autora traça um paralelo com o teatro, e exemplifica a partir das obras minimalistas no início dos anos 60, que por serem de uma sensibilidade literal, ou seja, não ilusionista, levavam em conta as circunstâncias reais do encontro entre obra e espectador, deslocando a atenção do objeto de arte para a experiência com obra ${ }^{3}$. Tal experiência da obra, segundo Duguet, era ainda mais potencial nos processos performativos ou cênicos quando operando aspectos de vigilância, pois, em um ambiente onde o privado se faz no público, a relação entre o que se vê e o que é autêntico é ainda mais complexa. É esse caráter que, por exemplo, Bruno irá ressaltar na materialidade das imagens contemporâneas de auto-exposição pública. Para a autora, essas são imagens que nos mantêm na sua superfície; como se não tivessem nada a revelar além do que se encontra exposto e "cujo princípio de visibilidade parece estender-se ao máximo" (BRUNO, 2013, p 81). São, portanto, imagens que revelam outra topologia, onde a interioridade não é mais a morada da verdade ou do desejo. Já Duguet cita como exemplo as instalações de Dan Graham, nas quais superfícies refletoras, como espelhos e vidros, ou sistemas de feedback em vídeo, tornam claro que ao saber-se visto e ver-se vendo é inevitável perceber-se parte da obra complicando a relação entre visibilidade e autenticidade. A autora destaca três operações essenciais em tais instalações que é possível reconhecer também operando o atual ambiente da vigilância distribuída: testar o espaço e o tempo, submetendo a jogos de registro, sutilezas do falso ao vivo, do passado o futuro anterior; confronto do espaço virtual imaterial com os espaços reais arquitetônicos; e o corpo do visitante como instrumento que ativa e revela o dispositivo, tornando visíveis seus processos e os modos pelos quais atua na percepção da obra. Nesse sentido, a obra passa a se apresentar como um processo realizado simultaneamente pelas modalidades de sua percepção e pelas modalidades de sua produção, tanto pelo artista quanto pelo o público.

Logo, ao pensar a reciprocidade entre os elementos dos dispositivos e as suas relações percebe-se que o sujeito individual não está no topo de um sistema de visibilidade supostamente 
vertical. Ao contrário, é tido como parte de um sistema horizontal, onde as dualidades interior e exterior, íntimo e exposto, público e privado, vigia e vigiado entram em colapso, quebrando a assimetria entre ver e ser visto instaurada no sistema moderno da estética da vigilância e inaugurando ainda novas possibilidades na relação entre sujeito-obra no contexto artístico contemporâneo.

\section{Cumplicidade:}

Eu estava espionando meu vizinho quando percebi que ele também estava me espionando. Isca:

ele só se põe a ver quando eu também me ponho.

Contrato:

me disponho vulnerável para me apropriar de ti.

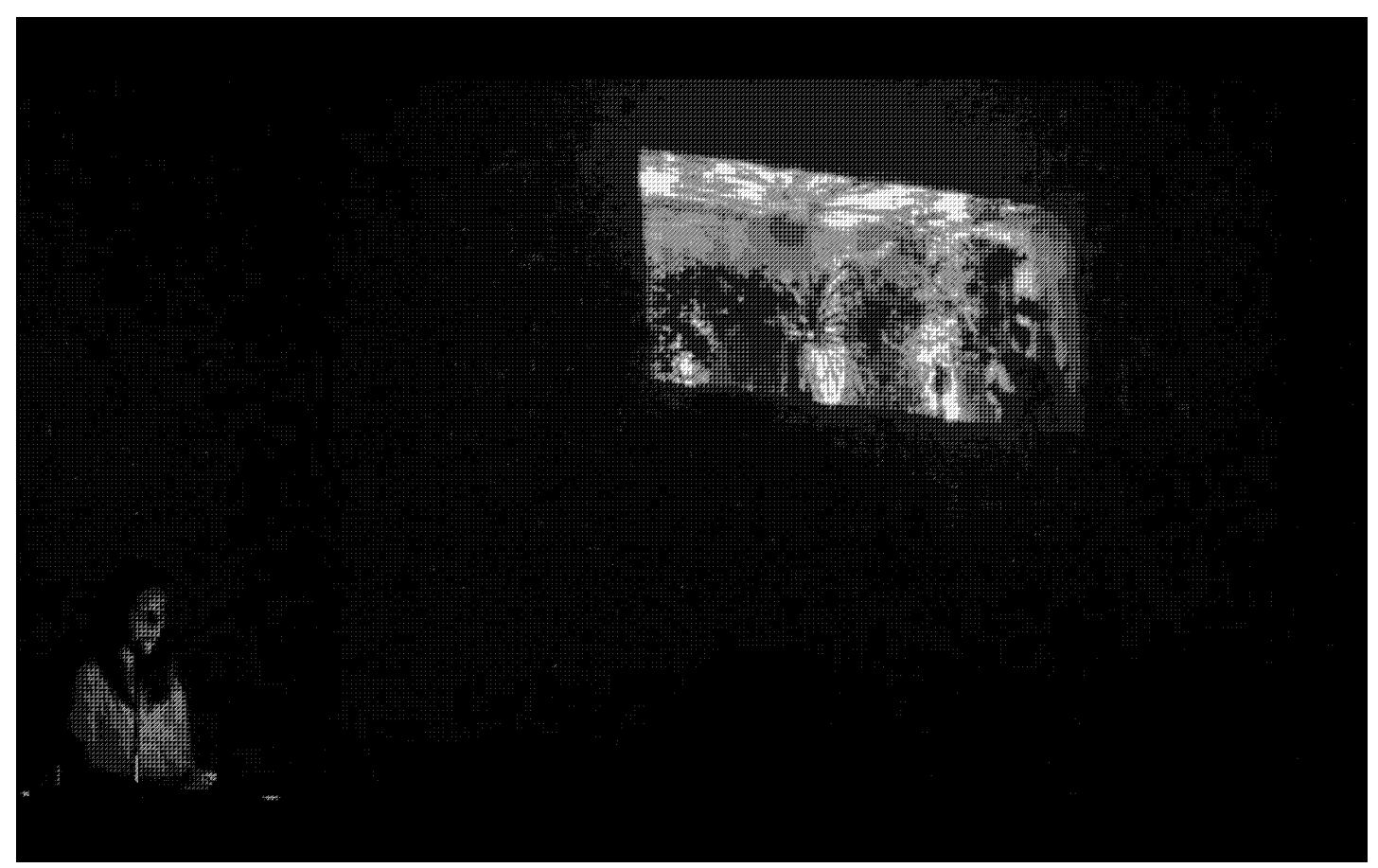

\section{Luiza Crosman}

Eu estava espionando meu vizinho quando, 2015.

Still de vídeo da comunicação oral performativa

(Fonte/fotógrafa: Lua Perê, 2015.) 
Antes de dormir pensei em Suite Vénitienne:

Sophie Calle seguiu um homem conhecido seu pelas ruas de Veneza por 13 dias. Registrou suas ações em foto e documentou suas próprias percepções - pessoais, objetivas, fantasiosas - em um diário. Fez do conjunto um livro. Muitos são os fatores em comum que encontro nessa obra, mas talvez as diferenças falem mais alto. Ao contrário de Sophie Calle não conheço meu vizinho, e não o sigo por entre diversas atividades. Não me sinto apaixonada por ele, nem desejo relatar suas ações para os outros. Minha curiosidade é pelo esquema espacial da minha espionagem, que diz respeito mais ao que dessa ação é gerado, do que o que por ela é capturado. A espionagem de Calle é um dispositivo de intimidade e veracidade. É feita de transparências, e às vezes essas transparências servem a ocultar ou dissimular. A transparência também é um artifício de opacidade. A minha espionagem é feita de opacidades. A noite é extremamente presente. Os mundos não se tocam e a camada grossa de suposições nunca é rompida. Talvez por isso mesmo ela me sirva para questionar o que é olhar. É na opacidade que o ato de ver se revela.

\section{TRÊS}

Há ainda outro fator no rompimento dessa assimetria, que é também a inspiração para o conceito de distribuição atrelado à vigilância como proposto por Fernanda Bruno. A autora parte de estudos sobre cognição distribuída ${ }^{4}$ os quais propõem um modelo de cognição que contraria a noção de uma inteligência ou cognição atribuída à interioridade do indivíduo, ou seja, formada essencialmente em uma instância central de comando como, por exemplo, a consciência. Ao contrário, a cognição distribuída define-se por caracterizar a inteligência como a

\footnotetext{
"habilidade de espalhar nossas mentes pelo mundo, partilhando ações cognitivas com outros indivíduos e objetos técnicos, os quais não apenas cumprem tarefas dirigidas por nós, mas produzem, eles mesmos, diferenças e deslocamentos, transformando em retorno a nossa cognição" (BRUNO, 2013, p 26).
}

Assim, a cognição torna-se um processo transindividual, espraiado por múltiplos agentes (humanos e não humanos). Tal processo garante à vigilância contemporânea sua distribuição no tecido social de forma híbrida e heterogênea, produzindo sentidos afetivos e sociais, que 
possibilitam a produção de subjetividade do sujeito ao atrelar reputação, pertencimento, admiração, desejo, às formas como nos vemos e como nos dispomos a ser vistos. Ou seja, garante um processo onde ser visto constitui ser, em um processo no qual a subjetividade é produzida naquilo que se dispõe ao olhar do outro.

A passagem da vigilância moderna para a vigilância contemporânea se torna então um terreno fértil para pensar a performatividade como nova condição para a subjetividade do sujeito. Enquanto na perspectiva moderna a subjetividade estava ligada ao olhar vigilante, inclusive autovigilante, que visava expor o indivíduo comum a fim de normalizá-lo - e, no processo, gerando uma superfície de aparência a parte de uma interioridade de privacidade e verdade íntima -, na perspectiva contemporânea é na expressão da intimidade que se realiza o eu autêntico. Contudo, Bruno adverte:

É certo que mostrar é também uma forma de esconder, mas na superficialidade estética contemporânea o que é deixado para trás ou por trás da imagem, da aparência e do artifício não é necessariamente mais verdadeiro que o que se mostra (BRUNO, 2013, p.70).

Deste modo, a tríade visibilidade, autenticidade e subjetividade parece dobrar-se por cima de si mesma, criando uma nova relação topográfica que, ao invés de posicionar o indivíduo a parte do mundo, o percebe intrinsecamente formando e sendo formado por ele. Dispor-se ao olhar do outro é, já e constantemente, performar.

É a partir da Teoria dos atos de fala do filósofo inglês J. L. Austin que se torna possível romper com a compreensão da linguagem como veículo de comunicação e diferenciar o ato descritivo ou narrativo, ou seja, a linguagem constativa, do ato performativo, ou seja, a linguagem fazendo algo. A autora Ana Bernstein aponta em seu texto "Atos da fala, representação teatral e teorias da performance", como a teoria de Austin se torna um ponto de partida produtivo para a expansão dos pensamentos em performance, principalmente no seu entrecruzamento crítico com outras disciplinas. É, por exemplo, no encontro crítico de Judith Butler - teórica da performatividade de gênero e que reafirma as críticas de Jaques Derrida à Austin - que o ato ou elocução performativa é tido sempre como uma citação, que deriva sua autoridade da autoridade de atos previamente invocados, e seu orador, ao contrário do que diz Austin, não é o autor da fala, pelo contrário é "uma ilusão produzida pelo encobrimento da natureza citatória do ato" (BERNSTEIN, 2004, p.64). Nessa cadência, o ato performativo é, portanto, uma 
prática contextual e reiterativa pela qual a linguagem age sobre o mundo e o sujeito tem sua subjetividade produzida na interpelação com ele.

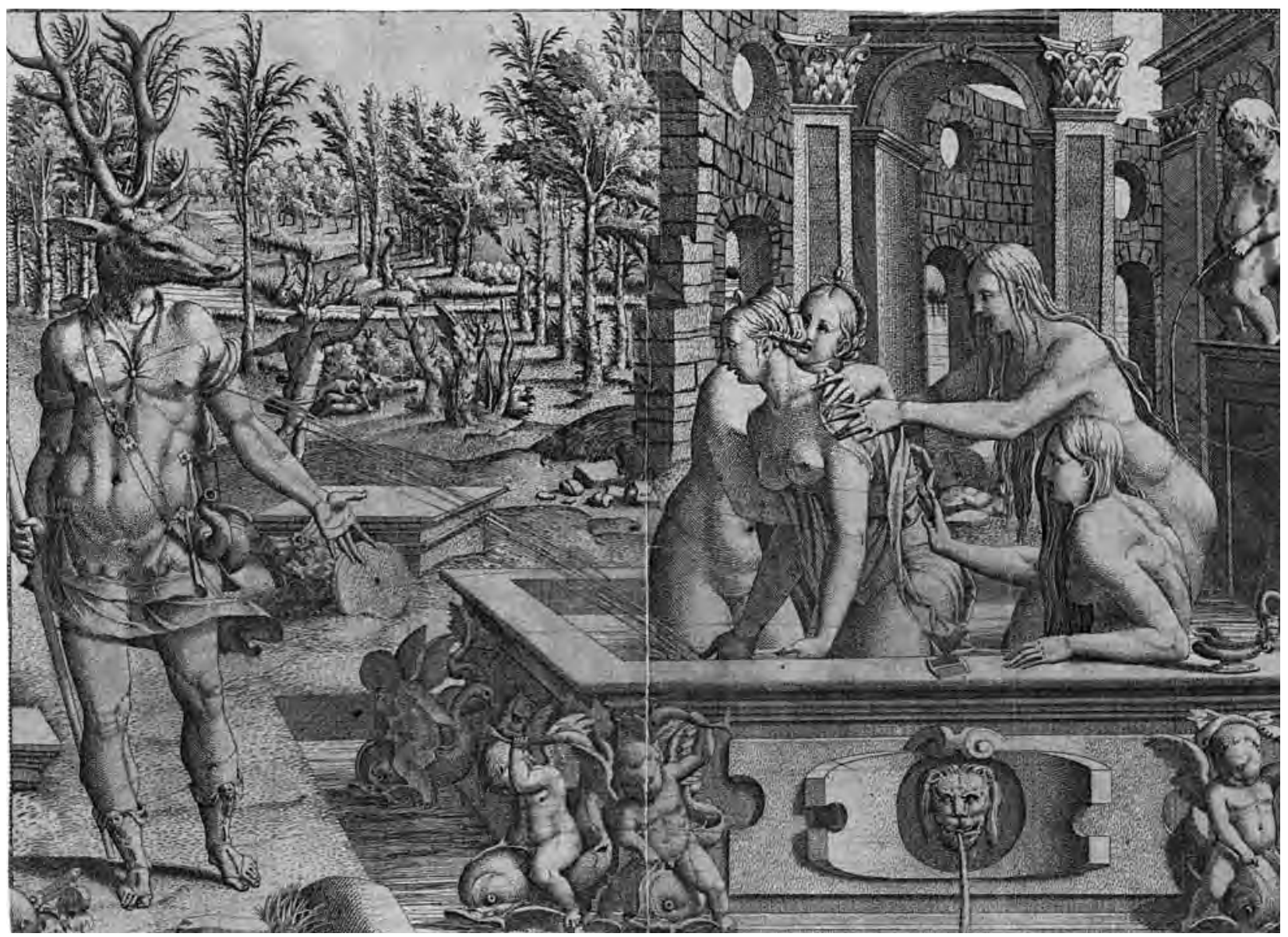

Jean Mignon

A Transformação de Actéon (com sua perseguição e morte ao fundo), sem data.

Gravura.

(Fonte: WIKIPEDIA) 
Volto à gravura da transformação do corpo de Actéon. Os três momentos sem retorno: o corpo em transformação, o corpo em fuga e o corpo em morte. Transformação? Actéon ainda se percebia como Actéon, mas era presa porque o caçavam.

Só o filmo quando estou presente para observá-lo. A duração dos vídeos informa o tempo que me pus disponível também ao seu olhar, mesmo que esse incida sem comprovação.

Esta latência me faz projetar histórias, embora saiba que minha atual condição de voyeur é antes um artifício de destino do que um artifício ilusão. Se este momento, aqui e agora, é ficção, então eu também o sou.

A produção de si através da relação com o mundo é uma noção que também aparece na definição de corpo que a performer Eleonora Fabião faz a partir de Espinosa. Segundo a autora, o corpo não é uma entidade dada a priori, sendo, ao contrário, definido pelos afetos que é capaz de gerar, gerir, receber e trocar, ou seja, uma entidade relacional. Essa perspectiva reforça a proposição de um corpo-subjetividade, permanentemente em formação, inacabado, ou ainda, como coloca Fabião, inacabável. No contexto contemporâneo da performance, realizar um ato, ou programa, ${ }^{5}$ performativo é justamente promover uma experiência na qual conteúdo e significação são gerados por e através dos corpos, ao invés de apenas decodificados por eles. O corpo se encontra, portanto, em constante transmutação entre cena e não-cena, arte e não-arte.

Para Fabião, a potência da performance vem da possibilidade que esta traz de desabituar-nos ao buscar formas de lidar com o estabelecido e ao disseminar dissonâncias de ordem diversas, por exemplo, econômica, emocional, sexual, política, estética, etc. Logo, não é intuito da performance comunicar um conteúdo estabilizado ao espectador, ao contrário, é desestabilizar sua relação com o mundo a fim de criar novas significações a partir da potência da ação, ou seja, da realização do programa performativo. E, diferentemente de Bernstein, que enxerga também no teatro tradicional a possibilidade performativa, Fabião afirma que o programa adquire ainda mais potência quando conduz o cênico a situações representacionais limite, gerando um estado híbrido de encenação e perfomatividade. Pois é quando a performance é a 
ação em si mesma, e o artifício deixa de ser máscara para tornar-se um elemento constitutivo de significação, que ela emerge como experiência erguida tanto pelo performer quanto pelo espectador.

Percebe-se, similarmente ao processo da vigilância contemporânea, a dissolução da assimetria que antes caracterizava a cena tradicional: os sujeitos da ação e seus espectadores não têm mais seus papéis definidos a priori pelas mediações da cena tradicional (o roteiro, o ator, o palco, a dimensão representacional), mas os têm formulado em uma relação instável e aberta que toma partido do cênico limite ou cênico autorreferencial para trazer ainda mais um aspecto operado em obras performativas: a participação, ou ainda, cumplicidade extorquida de seus espectadores, que no deslocamento de sua subjetividade tornam-se, em maior ou menor grau, tão agentes da ação quanto o próprio performer. Antes, ambas as extremidades estavam protegidas por mediações que separavam os limites do olhar, aquilo que estava exposto, e, consequentemente, os processos de subjetivação que definiam os papéis. $\mathrm{Na}$ condição performativa, onde olhar é também tomar uma posição, a relação entre o que está visível e o que é visto é atravessada pelos dispositivos que a integram.

A interrupção se diz flagrante.

Não tenho interesse no flagrante, prefiro essa performance seca e sem assunto, como quando duas ou mais pessoas se vêem obrigadas a conviver por um curto período em espaços pequenos, tais como elevadores e salas de espera. Em ambientes como esses o olhar preenche tanto o espaço que é impossível não se perceber performando normalidade. Está tudo programado em um roteiro de generalidades.

(Nada dá mais nervoso do que perceber-se respirando).

A noite hoje está como de veludo. Surda e sensual. Fixo meu olhar no mesmo ponto de sempre, mas meu vizinho não aparece. Onde poderia estar o flagrante se na sua janela nada acontece? Que palavras sobrevivem à escuridão? Que ações acendem, incandescem na noite quente e abafada de dezembro? Passo horas encarando o prédio absorvido pela noite e aquela única janela acesa. Parece haver palavras que a madrugada não me deixa enxergar.

Emudeço deitada na cama. Umedeço apoiada na janela. 

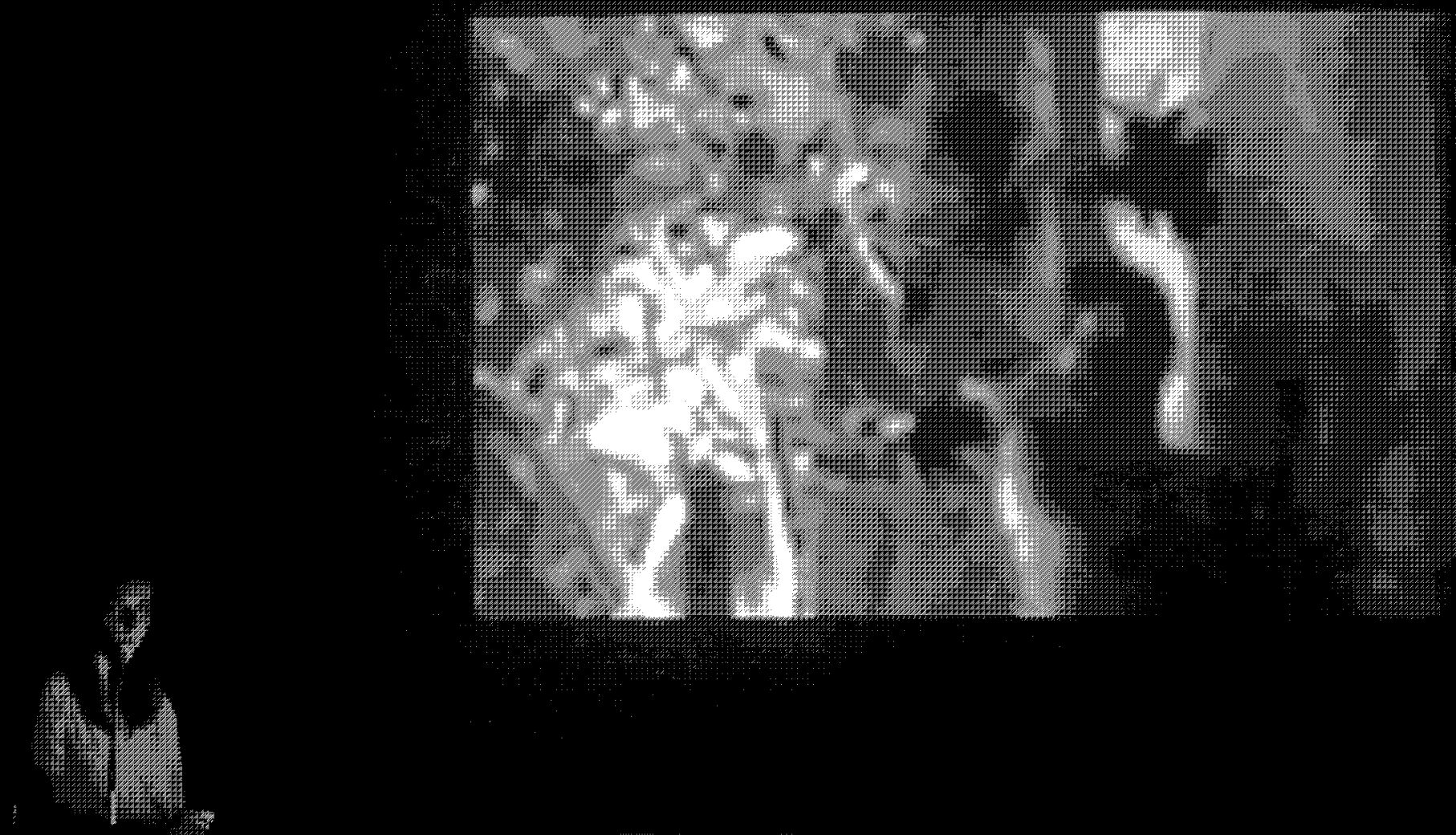

知

\section{Luiza Crosman}

Eu estava espionando meu vizinho quando, 2015.

Still de vídeo da comunicação oral performativa

(Fonte/fotógrafa: Lua Perê, 2015.) 


\section{QUATRO}

A performatividade operada pela cena-não-cena gera um deslocamento no corpo-subjetividade tanto daquele que exerce o enunciado quanto daquele na condição de espectador. E, ainda que no paralelo com a esfera da vigilância esse circuito seja traçado ao redor de noções específicas, como, por exemplo, da autoestima e dos cuidados de si, através de mecanismos de naturalização do olhar e auto-exposição, é esta mesma noção, de que a autenticidade é regida também pelos dispositivos que legitimam o estatuto do olhar contemporâneo, que opera a nova condição para a produção do corpo em performance: o olhar performa.

A noção de dispositivo de Duguet, que propõe a obra como sistema relacional, encontra àquela proposta por Bruno, e a rede de relação entre os elementos heterogêneos que a compõe e suas funções estratégicas é o que permite pensar não só os dispositivos de vigilância - ou da obra -, como também a própria vigilância como dispositivo - e, portanto, a obra idem. Não sendo mais um produto acabado, e sendo atualizada a cada experiência, a obra exige de seu público uma tomada de decisão frente a ela. Este, por sua vez, já inserido em um contexto mais abrangente de produção de subjetividade através da prática de auto-exposição e da legitimação de sua autenticidade através de um novo estatuto do olhar e do fazer-se através do ato de ser visto, não só é capturado como cúmplice, como aceita esta condição, ativando e sendo ativado pela obra.

Tais são aspectos decisivos que permitem ampliar o escopo de formas práticas performativas e, principalmente, seus contextos expositivos. Suas cenas não cenas, suas redes de dispositivos. E explorar essa potência performativa da linguagem é justamente refletir e experimentar sobre a corporeidade do mundo.

Ele me viu. Tenho certeza que me viu.

Artigo recebido em julho de 2015 e aprovado em agosto de 2015.

\section{NOTAS}

$1 \mathrm{~A}$ raiz do automonitoramento também recua historicamente a processos modernos nas suas organizações de ver e ser visto. De forma breve, a preocupação com aquilo do indivíduo que estava disposto aos olhos do outro, primeiramente em termos de higiene, vai de forma progressiva, sendo incorporado à esfera íntima e privada do indivíduo, que passa a percorrer um campo de cuidados consigo, autocontrole e autovigilância. 
2 Muitas dessas experimentações se originam em princípios da vídeo-vigilância, por exemplo, o olhar maquínico, impessoal e dessubjetivado, como indicado tanto por Duguet (2009) quanto por Bruno (2013) ao tratar em seu livro de algumas obras em arte contemporânea.

30 ponto de vista privilegiado, outra preocupação do teatro nos anos 60 que ressoa nas mudanças ocorridas no ato de olhar vigilante contemporâneo, também é posto em questão. Seja pela simultaneidade de cenas ou ações, seja pela dispersão dos elementos constituintes da obra. Nessa concepção contemporânea, a experiência acontece através de uma imbricada relação com o tempo, desde antecipação e memória, por parte do espectador, a desgaste físico ou extensão de limites por parte do artista (Duguet, 2009).

4 Referência dada pela autora: HUTCHINS, E. Cognition in the Wild. 2a ed. Massachusetts: MIT, 1996; e CLARK, A. Being There: Putting Brain, Body and World Together Again. MIT Press, 1997.

5 Eleonora Fabião chama o procedimento de apresentar uma performance de "programa", inspirada pelo uso da palavra por Gilles Deleuze e Félix Guattari no texto "Como criar para si um Corpo sem Órgãos". Neste texto os autores sugerem que o programa é o "motor da experimentação", pois "cria corpo e relações entre corpos; deflagra negociações de pertencimento; ativa circulações afetivas impensáveis antes da formulação e execução do programa" (Fabião, 2008). A autora segue definindo programa como "um tipo de ação metódicamente calculada, conceitualmente polida, que em geral exige extrema tenacidade para ser levada a cabo, e que se aproxima do improvisacional exclusivamente na medida em que não seja previamente ensaiada" (Fabião, 2008).

\section{Referências:}

BERSTEIN, Ana. Atos da fala, representação teatral e teorias da performance. In: Teatro do Pequeno Gesto, n.20, 2004.

BRUNO, Fernanda. Máquinas de ver, modos de ser: vigilância, tecnologia e subjetividade. Porto Alegre, Editora Sulina, 2013.

DUGUET, Anne-Marie. Dispositivos. In: MACIEL, Katia. (Org) Transcinemas. Rio de Janeiro, RJ: Contra Capa Livraria, 2009.

FABIÃO, Eleonora; "Performance e teatro: poéticas e políticas da cena contemporânea" in Revista Sala Preta v. 8, n. 1, p. 235-246, 2008. 